\title{
Four strategies to find, evaluate, and engage with online resources in emergency medicine
}

\author{
Andrea Lo, MD*; Eric Shappell, $\mathrm{MD}^{\dagger}$; Hans Rosenberg, MD*; Brent Thoma, MD, MA, MSc ${ }^{\ddagger}$; \\ James Ahn, MD, MHPE ${ }^{\dagger}$; N. Seth Trueger, MD, MPH ${ }^{\S}$; Teresa M. Chan, HBSc, BEd, MD, MHPE ${ }^{\mathbb{N}}$
}

\section{ABSTRACT}

Despite the rapid expansion of online educational resources for emergency medicine, barriers remain to their effective use by emergency physicians and trainees. This article expands on previous descriptions of techniques to aggregate online educational resources, outlining four strategies to help learners navigate, evaluate, and contribute online. These strategies include 1) cultivating digital mentors, 2) browsing the most popular free open access medical education (FOAM) websites, 3) using critical appraisal tools developed for FOAM, and 4) contributing new online content.

\section{RÉSUMÉ}

Malgré la croissance rapide des ressources didactiques en ligne en médecine d'urgence, il existe encore des obstacles à leur utilisation efficace par les urgentologues et les stagiaires. Aussi expliquons-nous davantage en détail, dans l'article, des techniques déjà décrites de collecte de ressources didactiques en ligne, et mettons-nous de l'avant quatre moyens pour aider les apprenants à naviguer dans les sites, à les évaluer et à ajouter du nouveau contenu en ligne. Ces moyens consistent : 1) à trouver des mentors dans un environnement numérique; 2) à naviguer dans les sites Web de formation médicale en libre accès, les plus visités; 3) à utiliser les outils d'évaluation critique conçus pour ces derniers sites; et 4) à ajouter du nouveau contenu en ligne.

Keywords: free open access medical education (FOAM), online educational resources

\section{INTRODUCTION}

In the past decade, there has been a substantial increase in the number ${ }^{1}$ and utilization ${ }^{2-3}$ of online educational resources by health care practitioners, particularly in emergency medicine (EM). These resources include subscription-based content by formal educational organizations such as medical schools and journals, medical websites produced by individuals or groups of educators, and content posted on general open-access platforms such as Facebook, YouTube, and Wikipedia.
These resources are meant to complement traditional learning from textbooks, primary literature, and on-shift learning.

The subset of these resources that are openly accessible online has been dubbed "free open access medical education" (FOAM). ${ }^{4}$ The origins of this movement stem beyond the inception of the term FOAM in 2012, ${ }^{4}$ as evidenced by the prevalence of EM and critical care blogs that emerged before the time in which the term was coined. ${ }^{1}$ This paper focuses on these freely accessible online resources and in particular, the websites, blogs, podcasts, videos, and social media outlets that make up this online community. While subscription-based or pay-walled resources have similar educational goals, they have been excluded from this term as they are not universally accessible or open to contributions.

Previously, Thoma and colleagues described strategies for learners to collate and aggregate online resources using a number of digital tools. ${ }^{5}$ Since then, there has been a growing trend in the FOAM movement to enhance the quality of material using checklists, ${ }^{6}$ rating systems, ${ }^{7-8}$ and peer reviews. ${ }^{9,10}$ Rapid development in this area has changed the landscape for users attempting to identify the most useful resources, appraise content critically, and contribute to content. This article outlines four strategies to help users find reliable FOAM resources, critically evaluate these resources, and participate in the FOAM movement.

\section{Strategy one: cultivate digital mentors}

Traditionally, learners have cultivated mentors from their local medical school and residency program, their

From the *Department of Emergency Medicine, University of Ottawa, Ottawa, ON; †Section of Emergency Medicine, Department of Medicine, University of Chicago, Chicago, IL; ‡Department of Emergency Medicine, University of Saskatchewan, Saskatoon, SK; §Department of Emergency Medicine, Northwestern University, Chicago, IL; and the IDivision of Emergency Medicine, Department of Medicine, McMaster University, Hamilton, ON.

Correspondence to: Dr. Andrea Lo, Department of Emergency Medicine, Humber River Hospital, 1235 Wilson Ave, Toronto, ON M3M 0B2; Email: drandreaylo@gmail.com 
elective rotations, and possibly conferences and other networking opportunities. With the large growth in online education within our specialty of EM, there is vast potential for digital mentorship in the FOAM community. Digital mentors are online accounts that learners can follow that serve several mentorship roles. First, they help steer learners toward new resources and other community members to follow. Second, by observing and interacting with these mentors, learners can benefit from role modelling, such as how to contribute to the online community, access FOAM material sustainably, and integrate this learning into practise.

Mentors may range from local to international in scope, from single author accounts to FOAM sites with teams of editors, and from general EM topics to specialty niches in EM. Each learner can personalize their choices for digital mentors to meet their learning goals. To start, learners can seek out websites and social media accounts representing their local department, residency program, or regional and national medical bodies. Next, learners can follow notable blogs, podcasts, and social media accounts for individual medical educators whom they consider to be mentors. Lastly, learners can identify FOAM resources of interest, whether in general or a specialty area of EM, and follow the social media accounts of these sites and their editors.

While the online EM community crosses multiple platforms and websites, attempting to use a variety of these can be overwhelming. Twitter is arguably the current "virtual town hall" of the FOAM community where novices and mentors interact and share ideas, making it an ideal place to start seeking out digital mentors. A recent network analysis showed how certain participants on Twitter could help to connect users to new ideas or people. ${ }^{12}$ Such analyses may hold value for those who are seeking mentors. By observing and interacting with these accounts on social media platforms such as Twitter, learners benefit from the mentorship roles mentioned above.

\section{Strategy two: browse the most popular FOAM websites}

In virtual communities of practice, there is substantial sharing of information. As such, finding the highest yielding content can be difficult. General Web searches (e.g., Google, Bing, or Yahoo) are optimized for the lay population, but not for practising emergency physicians and trainees. While using custom search engines (e.g., FOAMsearch.net, also known as GoogleFOAM), ${ }^{13}$ RSS feeds and Twitter hashtags may help to filter resources for learners as mentioned in previous publications ${ }^{5}$; it can still be daunting to decide what to read.

As emergency physicians are well networked, ${ }^{14}$ their followership of certain online resources may suggest usefulness. Novices can start by looking at the most popular content among the entire community of FOAM as ranked by the Social Media Index (SMi) that can be found at the following link: https://www.aliem. com/social-media-index/. ${ }^{11}$ The SMi is built upon the premise that FOAM content is directed at the specific community of practising emergency physicians. Broad followership lends some credibility as the websites included on the SMi are of minimal interest to the general public but of significant interest to this community, and followership correlates with other measures of impact and value to the specialty (such as journal impact factor and pageviews of a website). ${ }^{11}$ The SMi is somewhat analogous to an impact factor for journals and h-index for scholars and is the only published tool for such a measure to date that was developed specifically for online resources. This comparative index is derived from three indicators: Alexa rank of the website, Twitter followers of the most prominent editor, and Facebook likes. ${ }^{11}$ The SMi is published on the ALiEM website and updated quarterly to capture the most popular and current FOAM sources (Figure 1). ${ }^{11}$

The SMi is controversial within the FOAM community. Criticisms of the SMi include: 1) it can be gamed through the purchase of Facebook and Twitter followers; 2) the Alexa Score, which makes up a significant portion of the ratings, is proprietary, US-centric, and opaque; and 3) the constituent elements of SMi measure popularity, not quality per se. ${ }^{15}$ These criticisms are fairly similar to those of impact metrics for medical journals. However, SMi is one of the few blog metrics that has evidence demonstrating that it is correlated with other measures of impact if applied to medical journals. ${ }^{11}$ While the relationship of the SMi with quality is being studied, the SMi is the most highly cited metric in the field and can at the very least direct learners to impactful, prominent, and generally respected resources within the EM community.

\section{Strategy three: use existing critical appraisal tools developed for FOAM}

Since the start of the evidence-based movement in the late twentieth century, critical appraisal of scientific 


\begin{tabular}{|c|c|c|c|c|c|c|c|c|}
\hline $\begin{array}{l}\text { June } \\
15 .\end{array}$ & $\begin{array}{l}\text { Nov } \\
15 .\end{array}$ & $\begin{array}{l}\text { June } \\
16 .\end{array}$ & $\begin{array}{l}\text { Nov } \\
16 .\end{array}$ & Hyperlink & Alexa $=$ & Twitter $*$ & Facebook $=$ & $\begin{array}{l}\text { Social } \\
\text { Media } \\
\text { Index }\end{array}$ \\
\hline 1 & 1 & 1 & 1 & $\begin{array}{l}\text { Life in the Fast } \\
\text { Lane }\end{array}$ & 14686 & 18900 & 19656 & 9.4 \\
\hline 2 & 2 & 2 & 2 & EMcrit & 235690 & 29690 & 19207 & 6.93 \\
\hline 3 & 3 & 3 & 3 & $\begin{array}{l}\text { Academic Life in } \\
\text { EM }\end{array}$ & 288422 & 14251 & 20177 & 6.62 \\
\hline 4 & 5 & 4 & 4 & EMS 12 lead & 1231875 & 17292 & 105875 & 6.1 \\
\hline 6 & 6 & 6 & 5 & Dr Smith ECG & 989175 & 8674 & 30927 & 5.81 \\
\hline 13 & 10 & 7 & 6 & $\begin{array}{l}\text { Emergency } \\
\text { Medicine Cases }\end{array}$ & 713467 & 3669 & 15343 & 5.65 \\
\hline 9 & 9 & 8 & 7 & REBEL EM & 867307 & 10476 & 4061 & 5.52 \\
\hline 16 & 12 & 9 & 8 & $\begin{array}{l}\text { Intensive Care } \\
\text { Network }\end{array}$ & 1291531 & 9999 & 5753 & 5.35 \\
\hline 23 & 20 & 12 & 9 & EM Docs & 561184 & 3130 & 1873 & 5.33 \\
\hline 5 & 15 & 10 & 10 & St. Emlyns & 1496115 & 11560 & 3060 & 5.17 \\
\hline 12 & 16 & 11 & 11 & CanadiEM & 1104588 & 5041 & 1332 & 4.97 \\
\hline 15 & 14 & 14 & 12 & $\begin{array}{l}\text { Ultrasound } \\
\text { Podcast }\end{array}$ & 1822700 & 10851 & 1341 & 4.88 \\
\hline
\end{tabular}

Figure 1. Social Media Index ranking for November, 2016

literature has become better integrated into medical school and residency curricula. ${ }^{16}$ Scientific articles may be appraised using tools such as the $7 A M A$ Users' Guide to the Medical Literature ${ }^{17}$; however, secondary resources such as lectures and textbooks are seldom held to such standards. Blogs and podcasts follow in the tradition of secondary educational resources but are met with disproportionate skepticism, likely because of their novel and disruptive nature. ${ }^{18}$ In addition, by the nature of being open access, the wide availability of the internet, and with the ease of online publication, there are inevitably many FOAM articles and resources that are purely opinion based and lacking in quality evidence. Therefore, as the reach of these resources continues to expand rapidly, new tools and additional training are needed to assist with their critical evaluation, as gestalt ratings have proven unreliable. ${ }^{19,20}$

Tools including the DISCERN score ${ }^{21}$ and Health On the Net (HON) Code of Conduct ${ }^{22}$ have been developed to appraise online resources for patient use. Along similar lines, a number of recent studies have developed and examined quality indicators for online medical education resources. Three resulting critical appraisal systems have been published in the literature to date. The first is the Quality Checklists for Blogs and Podcasts. ${ }^{6}$ The checklists are qualitative sets of criteria that learners can apply to appraise critically specific online content for their personal learning. These checklists were derived from recently published studies on blog and podcast quality indicators (a systematic review, ${ }^{23}$ an expert Delphi with podcasters and bloggers, ${ }^{24}$ and a Delphi with expert educators ${ }^{25}$ ).

The second is the METRIQ score. ${ }^{8}$ A recent derivation study proposed two shortened scores named METRIQ5 and METRIQ8 that are more efficient for individuals seeking to evaluate online educational resources. ${ }^{8}$ Lastly, the ALiEM Approved Instructional Resources (AIR) score, ${ }^{26}$ has also been shown to be reliable and consistent with expert educator opinions of quality, if used by a calibrated team. ${ }^{7,8}$ The AIR Score was developed by the ALiEM group of educators to help select high-quality FOAM resources for their self-study curriculum, the ALiEM AIR Series. The AIR Score was derived through consensus by medical educators involved in the curation and production of FOAM. It has been determined to have reasonable 


\begin{tabular}{|c|c|}
\hline Critical appraisal systems & Description \\
\hline $\begin{array}{l}\text { HON code of conduct for medical } \\
\text { and health websites }\end{array}$ & $\begin{array}{l}\text { The HON Foundation is a non-governmental organization that has sought to certify high-quality health } \\
\text { information sites for the public. Its code of conduct includes a list of quality indicators that may help a user } \\
\text { to appraise a website before use. Its accreditation of a site can be used as a marker of quality. }\end{array}$ \\
\hline DISCERN score ${ }^{21}$ & $\begin{array}{l}\text { This is an older score that was derived to assist physicians and patients in determining whether resources are } \\
\text { "useful and appropriate" for informing treatment decisions. It has been shown to have reasonable reliability. } \\
\text { Appraisers of FOAM may find section one on publication reliability most relevant. }\end{array}$ \\
\hline \multirow[t]{2}{*}{ ALiEM AIR score 7,26} & $\begin{array}{l}\text { The AIR Score was developed by the ALiEM group of educators to help select high-quality FOAM } \\
\text { resources for its self-study curriculum, the ALiEM AIR Series. }\end{array}$ \\
\hline & $\begin{array}{l}\text { The AIR Score was derived through consensus by medical educators involved in the curation and } \\
\text { production of FOAM. It has been determined to have reasonable reliability with nine raters and to } \\
\text { correlate with expert educator gestalt. It has not yet been validated for use among non-educators or } \\
\text { learners. }\end{array}$ \\
\hline $\begin{array}{l}\text { Quality checklists for blogs and } \\
\text { podcasts }\end{array}$ & $\begin{array}{l}\text { The checklists are qualitative sets of criteria that learners can apply to appraise specific online content } \\
\text { critically for their personal learning. These checklists are based on recently published studies on blog and } \\
\text { podcast quality indicators (a systematic review, an expert Delphi, and an educator's Delphi). }\end{array}$ \\
\hline The METRIQ Scores ${ }^{8}$ & $\begin{array}{l}\text { A recent derivation study proposed two shortened scores (METRIQ5 and METRIQ8) that are more } \\
\text { efficient for individuals seeking to evaluate online educational resources. These are currently } \\
\text { undergoing prospective validation. }\end{array}$ \\
\hline
\end{tabular}

reliability with nine raters and to correlate with expert educator gestalt. It has not yet been validated for use among non-educators or learners. ${ }^{7,26}$ Ongoing studies are presently looking to assess the validity evidence supporting the METRIQ scores and to begin to optimize these quality assessment tools for widespread adoption.

The ubiquity of online education resources in $\mathrm{EM}$ education ${ }^{1-3}$ makes it important for teachers to consider the role of critical appraisal skills that are required for this unique genre of information. Table 1 summarizes some tools of importance for teachers who wish to address the issue of critical appraisal with their learners. It may be worthwhile to use structured appraisal tools such as METRIQ or ALiEM AIR scores ${ }^{8,26}$ and Quality Checklists for Blogs and Podcasts ${ }^{6}$ during residency training. While the evidence regarding these scores is mounting, faculty-guided discussions around how best to appraise and apply knowledge from these secondary resources can help junior learners develop skills at critically considering online resources. In the future, these evaluation instruments may guide producers of FOAM materials to improve their resources and allow institutions to have a more objective measure for the quality of FOAM content.

\section{Strategy four: participate by contributing and producing}

Beyond navigating and evaluating online educational resources, learners can further engage in the FOAM community by participating in discussion, criticism, peer review, and creation of open educational products.

As an alternative to creating a new website or podcast to host content, new developers should consider contributing new content to existing resources (Table 2). Not only will this save content developers the time and effort of creating a new platform, but also many of these sites incorporate a peer-review process to provide feedback and coaching for new contributors. Finally, these resources will offer a considerably larger readership for newly contributed material than most new sites.

Other practical and valuable ways of contributing to FOAM resources include participating in the peer review of content, reporting errors in blogs or podcasts to authors, commenting and engaging in a debate, and participating in discussions by joining in Tweet chats ${ }^{27}$ and online journal $\operatorname{clubs}^{28}$ (e.g., \#JGMEScholar ${ }^{29}$ and \#ALiEMJC ${ }^{30}$ ).

\section{Next steps}

The online education landscape is rapidly evolving. Some academic institutions are starting to support the production of open educational resources that have lead to the continued success of several prominent FOAM resources such as Core EM, which is supported by New York University, ${ }^{31}$ and Emergency Medicine Cases, which is supported by the University of Toronto 


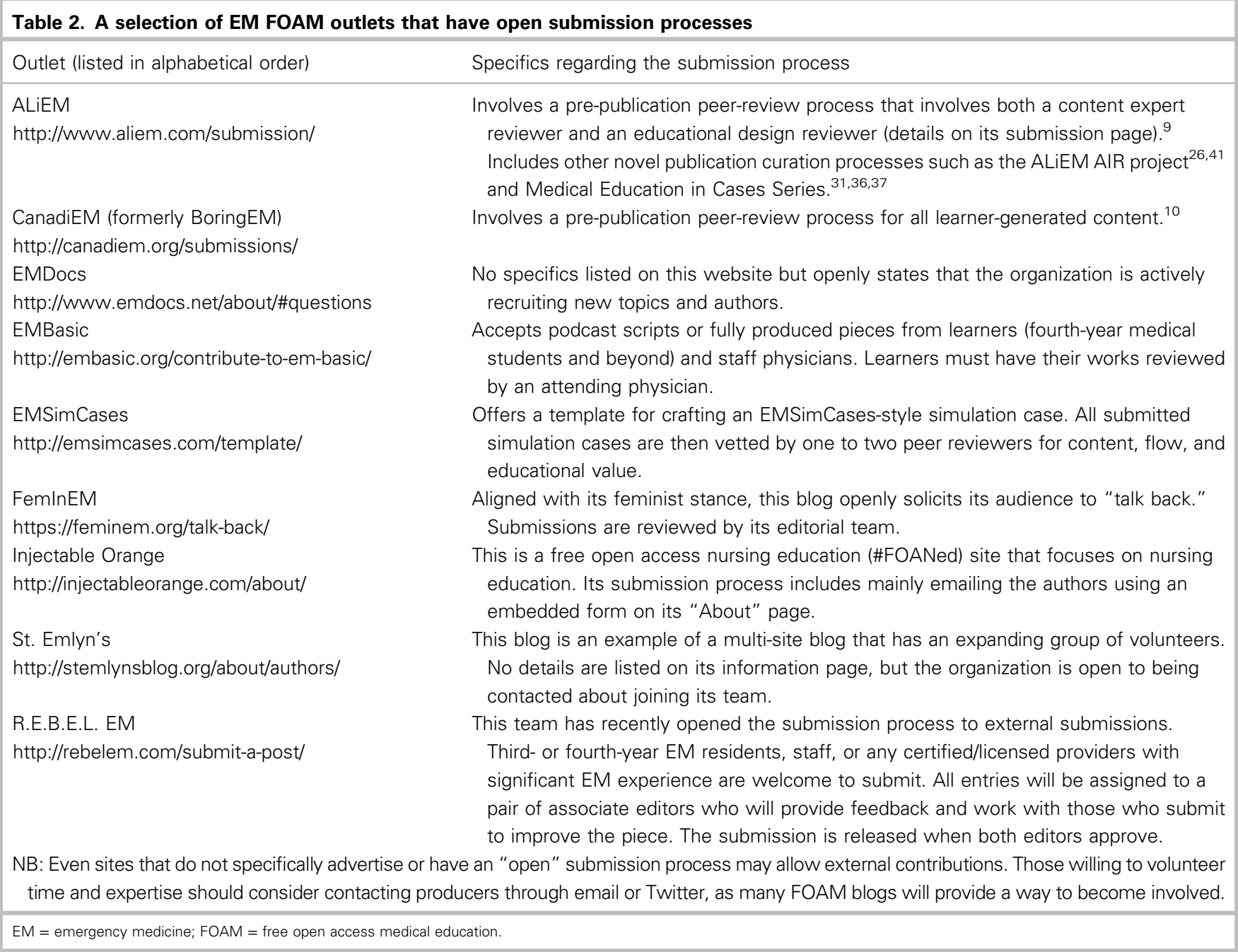

Division of Emergency Medicine and the Schwartz/ Reisman Emergency Medicine Institute. ${ }^{32}$ New definitions of scholarship are now created by international consensus, highlighting key changes on how online educational resources might be reconceptualized as scholarly work by academic institutions. ${ }^{33}$ Additionally, some institutions have begun rewarding the development of FOAM products as recognized acts of scholarship that add value toward promotion. ${ }^{34}$

We encourage both educators and learners to use the strategies in this article to integrate the use of FOAM into their teaching and continuing medical education (CME). Innovative teaching strategies using FOAM, such as the "flipped classroom," are increasingly described in medical education literature..$^{35,36}$ The appearance and popularity of FOAM-related projects such as online journal clubs ${ }^{28-30}$ suggest both interest and advantage in these novel self-learning formats.
Notably absent from the menu of strategies presented within this article is guidance on how to find and evaluate educational videos. While many resource producers embed videos from Vimeo ${ }^{\mathrm{TM}}$ or YouTube $^{\mathrm{TM}}$ onto their websites, many video-based resources are uploaded directly to video-hosting websites. Research in this area is sorely needed, as contrary to blog posts and podcasts, there are currently no guidelines to assist in the production or critical appraisal of these resources, nor are there strategies to find high-quality channels.

To foster FOAM integration into formal medical education, it will be important to develop a more rigorous approach for content production and evaluation techniques. While we describe advancements in the assessment of production quality, further development of more robust measures of educational quality and tools for learner evaluation is warranted. Those 
motivated to pioneer in this niche may benefit from incorporation of existing educational techniques such as identifying a target audience and subject matter, developing a formal curriculum (e.g., using Kern's six-step framework), ${ }^{37}$ and incorporating measures for evaluating learners beyond attitudinal data (e.g., using Kirkpatrick levels of evaluation). ${ }^{38}$

\section{CONCLUSIONS}

It is an exciting time to be both an EM practitioner and a citizen of the online community. We have presented four strategies for navigating and evaluating online resources for medical learners at all levels. Because of the ease of publication in the online environment, vigilance around these resources should be maintained, and we emphasize that FOAM resources only complement and do not replace traditional learning from textbooks and reading of primary literature. However, both educators and learners should be familiar with the critical appraisal processes and thoughtful educational design of FOAM to become informed consumers and producers of online educational resources - a medium of medical education that is only expanding in its impact on the practise of EM.

Competing interests: NST reports receiving stipends for his roles as a Social Media Editor for Annals of Emergency Medicine and Emergency Physicians Monthly. BT is the founder and editor of CanadiEM.org, as well as an editor at ALiEM.com and EMSimCases.com. TC is an associate editor at ALiEM.com and a senior editor at CanadiEM.org, writes and assists with FeminEM.org and Emergency Medicine Cases, and has received teaching honorariums for her duties within the ALiEM Faculty Incubator.

\section{REFERENCES}

1. Cadogan M, Thoma B, Chan TM, Lin M. Free Open Access Meducation (FOAM): the rise of emergency medicine and critical care blogs and podcasts (2002-2013). Emerg Med 7 2014;31(e1):e76-7.

2. Purdy E, Thoma B, Bednarczyk J, Migneault D, Sherbino J. The use of free online educational resources by Canadian emergency medicine residents and program directors. CFEM 2015;17(2):101-6.

3. Thurtle N, Banks C, Cox M, Pain T, Furyk J. Free Open Access Medical Education resource knowledge and utilisation amongst Emergency Medicine trainees: A survey in four countries. Afri $\mathcal{7}$ Emerg Med 2015;6:12-7.

4. Nickson CP, Cadogan MD. Free Open Access Medical education (FOAM) for the emergency physician. Emerg Med Australas 2014;26(1):76-83.
5. Thoma B, Joshi N, Trueger NS, Chan TM, Lin M. Five strategies to effectively use online resources in emergency medicine. Ann Emerg Med 2014;64(4):392-5.

6. Paterson QS, Colmers IN, Lin M, Thoma B, Chan T. The quality checklists for health professions blogs and podcasts. The Winnower 2015;2:e144720.

7. Chan TM, Grock A, Paddock M, Kulasegaram K, Yarris LM, Lin M. Examining reliability and validity of an online score (ALiEM AIR) for rating free open access medical education resources. Ann Emerg Med 2016;68(6): 729-35.

8. Chan TM, Thoma B, Krishnan K, et al. Derivation of two critical appraisal scores for trainees to evaluate online educational resources: A METRIQ Study. West 7 Emerg Med 2016;17(5):574-84.

9. Thoma B, Chan T, Desouza N, Lin M. Implementing peer review at an emergency medicine blog: bridging the gap between educators and clinical experts. C7EM 2015; 17(2):188-91.

10. Sidalak D, Purdy E, Luckett-Gatopoulos S, Thoma B, Chan TM. Coached Peer Review: Developing the Next Generation of Authors. Acad Med 2016;92(2):201-4.

11. Thoma B, Sanders JL, Lin M, et al. The social media index: measuring the impact of emergency medicine and critical care websites. West 7 Emerg Med 2015;16(2):242-9.

12. Riddell J, Brown A, Kovic I, Jauregui J. Who are the most influential emergency physicians on Twitter? West 7 Emerg Med 2017;18(2):281-7.

13. Raine T, Thoma B, Chan TM, Lin M. FOAMSearch.net: A custom search engine for emergency medicine and critical care. Emerg Med Australas 2015;27(4):363-5.

14. Kovic I, Lulic I, Brumini G. Examining the medical blogosphere: an online survey of medical bloggers. $7 \mathrm{Med}$ Internet Res. 2008;10(3):e28.

15. Thoma B. Social Media Index: Controversy and Evolution. Academic Life in Emergency Medicine. Available at: https:// www.aliem.com/2013/social-media-index-controversy-andevolution/ (accessed August 22, 2016).

16. CACMS Standards and Elements. Standards for Accreditation of Medical Education Programs Leading to the MD Degree March 2015. Ontario: Committee on Accreditation of Canadian Medical Schools (CACMS); 2014. Available at: https://www.afmc.ca/pdf/CACMS_Standards_and_Elements_ June_2014_Effective_July12015.pdf.

17. Guyatt G, Drummond R, Meade M, Cook DJ. Users' Guides to the Medical Literature: Essentials of Evidence-Based Clinical Practice. 3rd ed. New York: McGraw-Hill Education; 2015.

18. Thoma B, Chan T, Benitez J, Lin M. Educational scholarship in the digital age: a scoping review and analysis of scholarly products. The Winnower 2014;1:1-13.

19. Krishnan K, Thoma B, Trueger NS, Lin M, Chan TM. Gestalt assessment of online educational resources may not be sufficiently reliable and consistent. Perspect Med Educ 2017;6(2):91-8.

20. Thoma B, Sebok-Syer SS, Krishnan K, et al. Individual gestalt is unreliable for the evaluation of quality in medical education blogs: a METRIQ study. Ann Emerg Med 2017; epub, doi:10.1016/j.annemergmed.2016.12.025. 
21. Rees CE, Ford JE, Sheard CE. Evaluating the reliability of DISCERN: a tool for assessing the quality of written patient information on treatment choices. Patient Educ Couns 2002;47(3):273-5.

22. Boyer C, Selby M, Appel RD. The health on the net code of conduct for medical and health web sites. Stud Health Technol Inform 1998;52(Pt 2):1163-6.

23. Paterson QS, Thoma B, Milne WK, Lin M, Chan TM. A systematic review and qualitative analysis to determine quality indicators for health professions education blogs and podcasts. 7 Grad Med Educ 2015;7(4):549-54.

24. Thoma B, Chan TM, Paterson QS, et al. Emergency medicine and critical care blogs and podcasts: establishing an international consensus on quality. Ann Emerg Med 2015; 66(4):396-402.e4.

25. Lin M, Thoma B, Trueger NS, et al. Quality indicators for blogs and podcasts used in medical education: modified Delphi consensus recommendations by an international cohort of health professions educators. Postgraduate Medical Journal 2015;91:546-50.

26. Lin M, Joshi N, Grock A, et al. Approved Instructional Resources (AIR) Series: a national initiative to identify quality emergency medicine blog and podcast content for resident education. 7 Grad Med Educ 2016;8(2):219-25.

27. Choo EK, Ranney ML, Chan TM, et al. Twitter as a tool for communication and knowledge exchange in academic medicine: a guide for skeptics and novices. Medical Teach 2015;37(5):411-6.

28. Roberts MJ, Perera M, Lawrentschuk N, et al. Globalization of continuing professional development by journal clubs via microblogging: a systematic review. 7 Med Internet Res 2015;17(4):e103.
29. Lin M, Sherbino J. Creating a virtual journal club: a community of practice using multiple social media strategies. Fournal of Graduate Medical Education 2015;7(3): 481-2.

30. Lin M, Joshi N, Hayes BD, Chan TM. Accelerating knowledge translation: reflections from the online ALiEMAnnals Global Emergency Medicine Journal Club Experience. Ann Emerg Med 2017;69(4):469-74.

31. Swaminathan A, Core EM. Available at: http://coreem.net/ (accessed August 22, 2016).

32. Chartier LB, Helman A. Development, improvement and funding of the emergency medicine cases open-access podcast. Int 7 Med Educ 2016;7:340-1.

33. Sherbino J, Arora VM, Van Melle E, et al. Criteria for social media-based scholarship in health professions education. Postgrad Med 7 2015;91(1080):551-5.

34. Cabrera D. Mayo Clinic Includes Social Media Scholarship Activities in Academic Advancement. MCSMN Blog. Available at: https://socialmedia.mayoclinic.org/2016/05/25/ mayo-clinic-includes-social-media-scholarship-activities-inacademic-advancement/ (accessed June 17, 2017).

35. Sherbino J, Chan T, Schiff K. The reverse classroom: lectures on your own and homework with faculty. CFEM 2013;15(3):178-80.

36. Prober CG, Khan S. Medical education reimagined: a call to action. Acad Med 2013;88(10):1407-10.

37. Kern DE, Thomas PA, Hughes MT, eds. Curriculum Development for Medical Education: A Six-Step Approach. 2nd ed. Baltimore: The Johns Hopkins University Press; 2009.

38. Yardley S, Dornan T. Kirkpatrick's levels and education 'evidence.' Med Educ 2012;46(1):97-106. 